\title{
Planejamento governamental nos municípios brasileiros: em direção a uma agenda de pesquisa
}

\author{
LUCIANA LEITE LIMA ${ }^{1}$ \\ LIZANDRO LUI ${ }^{2}$ \\ Gianna Vargas ReIS Salgado Dias ${ }^{1}$ \\ LUCIANA PAZINI PAPI ${ }^{3}$ \\ Diogo Joel Demarco ${ }^{3}$
}

${ }^{1}$ Universidade Federal do Rio Grande do Sul (UfrgS) / Programa de Pós-graduação em Políticas Públicas, Porto Alegre - RS, Brasil

2 INSTITUTO DE PESQUISA ECONÔMICA APLICADA (IPEA), BRASÍLIA - DF, BRASIL

${ }^{3}$ Universidade Federal do Rio Grande do Sul (UFRGS) / Escola de AdMinistração, Porto Alegre - RS, Brasil

\section{Resumo}

A Constituição Federal de 1988 alçou os municípios à condição de entes federados autônomos, atribuiu-lhes uma série de competências em relação às políticas públicas e descentralizou a responsabilidade pela confecção de peças de planejamento governamental. Até então, este tipo de atividade, bem como as capacidades estatais correspondentes estavam concentrados na burocracia federal. Neste cenário de mudança institucional e organizacional, o objetivo deste artigo foi investigar a produção científica sobre o planejamento municipal. Para isso, realizamos uma busca sistematizada de artigos nas bases do Portal Periódicos Capes abrangendo o período de 1995 a 2018 . Os resultados evidenciaram que o campo é incipiente, carecendo de regularidade teórica e analítica, privilegia um viés normativo e está fortemente alicerçado em abordagens da administração de organizações privadas. Com isso, sustentamos a pertinência desta agenda de pesquisa, em consonância com a importância da gestão local para a federação e para a garantia de direitos.

Palavras-chave: Planejamento Governamental. Município. Descentralização. Capacidades Estatais. Políticas Públicas.

\section{Government planning in Brazilian municipalities: towards a research agenda}

\section{Abstract}

Brazil's Constitution of 1988 gave municipalities the status of autonomous federated entities. They were assigned a series of responsibilities in the field of public policies, including the duty of preparing government plans. Before the constitution, planning and the state capability regarding this task were concentrated in the federal bureaucracy. In this institutional and organizational changing scenario, the objective of this article was to investigate the scientific production regarding municipal planning. A systematized search of articles was carried out on the Portal Periódicos Capes databases for the period 1995 to 2018. The results showed that the field is incipient, lacking theoretical and analytical regularity, privileges a normative bias, and is strongly based on approaches developed in the field of business administration. This study corroborates the relevance of this research agenda. It stresses the importance of local management for the federation and the protection of rights.

Keywords: Government Planning. Municipality. Decentralization. State Capacities. Public Policies.

\section{Planificación gubernamental en los municipios brasileños: hacia una agenda de investigación}

\section{Resumen}

La Constitución de 1988 elevó a los municipios a la condición de entes federados autónomos, les atribuyó una serie de competencias en el campo de las políticas públicas, y descentralizó la responsabilidad por la confección de la planificación gubernamental. Hasta entonces, este tipo de actividad, así como las capacidades correspondientes de los estados estaban concentrados en la burocracia federal. En este escenario institucional y organizativo cambiante, el objetivo de este artículo fue investigar la producción científica sobre la planificación municipal. Para ello, realizamos una búsqueda sistematizada de artículos en las bases del Portal Periódicos Capes que abarcó el período de 1995 a 2018 . Los resultados evidenciaron que el campo es incipiente, carece de regularidad teórica y analítica, privilegia un sesgo normativo y está fuertemente basado en enfoques de la administración de organizaciones privadas. Con ello, sostenemos la pertinencia de esta agenda de investigación, en consonancia con la importancia de la gestión local para la federación y para la garantía de derechos.

Palabras clave: Planificación gubernamental. Municipio. Descentralización. Capacidades de los estados. Políticas públicas. 


\section{INTRODUÇÃO}

Há mais de um século o Brasil é uma federação. Adicionalmente, em 1988 os municípios foram elevados à categoria de entes federados, juntamente com a União e os estados. A partir daí um conjunto de mudanças políticas e institucionais ocorreram; dentre elas, um intenso processo de descentralização de políticas públicas. Em virtude disso, os municípios receberam uma gama de competências na condução de políticas de saúde, educação, assistência social, cultura, saneamento básico, que até então estavam sob responsabilidade dos órgãos do governo central. De forma concomitante, foram incumbidos da função de produzir peças orçamentárias e de planejamento, como o Planejamento Plurianual, a Lei de Diretrizes Orçamentárias (LDO) e o Plano Diretor.

Entretanto, sabe-se que as condições municipais no Brasil são distintas para atender ao conjunto de demandas constitucionais, uma vez que muitos são afetados pelo baixo desenvolvimento socioeconômico e pelas precariedades burocráticas e administrativas (GRIN, 2014; MARENCO e STROHSCHOEN, 2018). Ademais, a trajetória de produção de estruturas modernas de gestão, sobretudo voltadas ao planejamento, é recente na maioria dos municípios brasileiros, resultado, em grande parte, do legado pretérito de centralização desta atribuição pelo governo central. Assim, até 1988 a prática de planejamento governamental, por vezes intensa e por outras escassa, esteve concentrada nos órgãos federais, os quais foram responsáveis pela elaboração de diversos planos e projetos voltados, principalmente, para o objetivo do crescimento econômico (CARDOSO JUNIOR, 2011).

Neste quadro, este artigo almeja contribuir para o fortalecimento e desenvolvimento de uma agenda de pesquisa que lance luz sobre a gestão governamental nos municípios brasileiros. Trabalhando com a hipótese de que estes entes da federação carecem de capacidades estatais para o desenvolvimento das atividades de planejamento, em decorrência dos legados pretéritos da centralização, argumentamos que as atividades de planejamento são basilares para a expansão e qualificação da formulação e implementação de políticas públicas e que é necessário investigar de que forma os municípios vêm executando as competências correlatas. Tal premissa ganha relevo quando se leva em conta que o planejamento não era um conjunto de práticas familiares à gestão municipal. Diante disso, o objetivo deste artigo é investigar o planejamento governamental nos municípios brasileiros, seus processos e condições. Será abordado o planejamento em sua concepção mais abrangente, isto é, que contempla todas as atividades, intermediárias e finalísticas, de um governo; agregando as políticas setoriais e as atividades administrativas. Para isso, toma-se como foco a produção científica brasileira sobre a temática a partir do início da década de 1990. Desse modo, esta é uma pesquisa qualitativa, de caráter exploratório e descritivo, que utilizou dados secundários.

O artigo está organizado em quatro partes, além da introdução e da conclusão. Na primeira, discorremos sobre a trajetória do planejamento governamental no Brasil até a primeira dezena dos anos 2000, atentando para suas lógicas e contextos. Na segunda, concentram-nos nos municípios, ressaltando suas características e capacidades estatais para o planejamento. $\mathrm{Na}$ terceira, apresentamos os procedimentos metodológicos e, na quarta, expomos e discutimos os resultados da pesquisa.

\section{TRAJETÓRIA DO PLANEJAMENTO GOVERNAMENTAL NO BRASIL}

O planejamento governamental como instrumento de projeção e de modelagem do futuro vem sendo utilizado na administração pública, especialmente a partir do século XIX, quando os governos, tanto de países centrais quanto periféricos, passam a aplicá-lo como forma de promover o progresso econômico e social. Foi, porém, a partir da Primeira Guerra Mundial que o planejamento ganhou um teor estratégico, relacionado à alavancagem de transformações profundas nas sociedades. Foi o caso da União Soviética, que a partir de 1920 empreendeu esforços sistematizados para converter sua sociedade feudal em industrializada; assim como dos Estados Unidos, após a grande crise de 1929; também da Europa, no processo de reconstrução pós-Segunda Guerra Mundial. Nestes contextos, a prática do planejamento governamental estava centralizada no Estado e os governos centrais protagonizavam as dinâmicas de elaboração e de implementação. Esta observação é importante, porque tal monopolização marcará, também, a federação brasileira.

No Brasil, o planejamento governamental exibiu uma trajetória oscilante entre momentos de valorização e de pouca atenção. Teve-se, nesse movimento, dois períodos de declínio e dois de auge, alternadamente: declínio de 1889 a 1930, auge em meados de 1930 a 1970, declínio de 1980 a 1990, e auge a partir da primeira metade dos anos 2000 (CARDOSO JUNIOR, 2011; REZENDE, 2011). O primeiro período foi marcado por ações estatais pontuais e setoriais, direcionadas para administrar momentos de crise; o planejamento não tinha, portanto, caráter estratégico e amplo (CARDOSO JUNIOR, 2011). 
Já no segundo período, as ações de planejamento abrangente ganharam espaço a partir dos anos 1930, capitaneadas pelo governo central. Elas voltavam-se aos objetivos daquela época: garantir maior autonomia à economia brasileira em relação à estrangeira, assim como promover a industrialização (REZENDE, 2011). Para isso, alguns órgãos estatais foram criados, como o Departamento Administrativo do Serviço Público, o qual formulou o primeiro plano quinquenal brasileiro, o Plano Especial de Obras Públicas e Reaparelhamento da Defesa Nacional (1939-1943) e o Plano de Obras e Equipamentos (REZENDE, 2011). Na década de 1940 o desenvolvimento do planejamento seguiu um curso ascendente com a criação das primeiras estatais brasileiras: Companhia Vale do Rio Doce, a Petróleo Brasileiro S/A, as Centrais Elétricas Brasileiras e o Banco Nacional de Desenvolvimento Econômico. Ainda, em 1946, foi lançado o Plano Salte (1946), apontando áreas prioritárias para ação estatal, mas que, na prática, não foi executado (CARDOSO JUNIOR, 2011; REZENDE, 2011).

Entre as décadas de 1950 e 1970, o planejamento governamental fez-se presente de forma mais intensa, mas também diferenciada, uma vez que foi adotado por governos democráticos e pela Ditadura Civil-Militar. Em um primeiro momento, sua prática era intensiva e com caráter discricionário, tendo alcançado seu ápice em virtude dos esforços da Comissão Econômica para o Caribe e a América Latina (CEPAL) em disseminar prescrições desenvolvimentistas em ambos. No Brasil, tal receita expressou-se no Plano de Metas do governo de Juscelino Kubitschek. Já no politicamente conturbado governo de Jânio Quadros, que renunciou, e no de João Goulart, que assumiu a presidência em seguida, o planejamento governamental não encontrou terreno fértil para prosperar. O Plano Trienal de Desenvolvimento Econômico e Social foi a tentativa de planejamento governamental deste período, não tendo sido executado especialmente pela falta de apoio do Legislativo (CARDOSO JUNIOR, 2011; REZENDE, 2011).

A partir de 1964 até o final da década de 1970, as ações de planejamento governamental foram intensificadas, marcadas por um viés autoritário-tecnocrático e vertical. Elas conformaram instrumentos para a realização da grande reforma administrativa do Estado de $1967^{1}$, por meio da execução do Plano de Ação Econômica do Governo e da criação de três Planos Nacionais de Desenvolvimento (CARDOSO JUNIOR, 2011). Vale destacar que, a partir da metade da década de 1970, teve início a difusão do ideário neoliberal, cujo impacto só seria sentido no Brasil nas décadas que seguiriam. Tal conjunto de ideias, em seu formato político-administrativo com foco na gestão governamental, assentava-se numa visão essencialmente negativa do Estado e de sua ação (EVANS, 2004). Como resultado, as estruturas e instituições de planejamento governamental começaram a ruir e as poucas práticas concentravam-se em iniciativas de curto prazo, voltadas ao controle daquele que foi, por décadas, tratado como o problema social central do país: a inflação (CARDOSO JUNIOR, 2011). No que tange ao planejamento ao nível dos estados, Saddi (2003) aponta que o Governo Geisel criou um Programa de Cooperação Técnica, realizado entre 1974-1978, com o objetivo inicial de institucionalizar os Sistemas Estaduais de Planejamento e minimizar os problemas fiscais. Já a relação de cooperação técnica com os municípios ficaria a cargo dos governos estaduais.

A década de 1980 foi marcada por um paradoxo. Se, por um lado, a assunção do colapso do governo autoritário alimentou e fortaleceu a luta pela democracia e pelo Estado Social; por outro, o ambiente intelectual mundial era estimulado pelas ideias neoliberais sobre o funcionamento do Estado. Nesse cenário, a Constituição Federal de 1988 alçou o planejamento à atividade obrigatória dos governos, passando a uma perspectiva de curto e médio prazos e vinculado ao orçamento. Destarte, segundo Cardoso Junior (2011), o planejamento passou a fazer parte, formalmente, das práticas cotidianas da administração pública; devendo, inclusive, funcionar como elo entre governos, criando convergência entre alternância democrática e administração pública estável.

Entre os anos de 2000 a 2010, a prática de planejamento intensificou-se com a execução dos Planos Plurianuais (PPA) nos três entes federados e com a criação de órgãos de planejamento, como a Secretaria de Assuntos Estratégicos da Presidência da República. Também foram elaborados e implementados pelo governo federal dois Programas de Aceleração do Crescimento (em 2007 e em 2011) com o objetivo de retomar o investimento público em infraestrutura urbana, social, logística e energética (REZENDE, 2011). Além disso, em 2010, a Secretaria de Assuntos Estratégicos da Presidência da República formulou, mas não executou, um plano de longo prazo para a geração de desenvolvimento econômico e social. Nesse plano foram estabelecidas metas para diversos setores, como infraestrutura, segurança pública, saúde, educação, agricultura, administração estatal, relações internacionais, transparência pública e sistema tributário (CARDOSO JUNIOR, 2011).

Esta breve explanação sobre a trajetória do planejamento governamental no Brasil mostra o papel preponderante do governo central. Tal centralização de capacidades estatais de planejamento no âmbito federal não ficou imune a críticas quanto a suas disfunções (CARDOSO JUNIOR e SANTOS, 2018) e sua incompletude organizacional enquanto sistema (COUTO e MAGALHÃES, 2017).

\footnotetext{
${ }^{1}$ Tal reforma ocorreu no âmbito federal por meio do Decreto-Lei № 200, de 25 de fevereiro de 1967 (BRASIL, 1966)
} 
Neste trabalho sustentamos que uma decorrência desta centralidade foi a escassa atenção recebida pelos governos locais nos estudos científicos sobre o tema, como veremos a seguir. Certamente o lugar do planejamento municipal e mesmo estadual na história do planejamento governamental no Brasil está relacionado com a posição e os papéis que ocuparam na federação ao longo do tempo. No caso dos municípios, por terem conquistado autonomia relativamente mais tarde, a situação é ainda mais aguda no que concerne à carência de instrumentos de planejamento. Sobre isso, Noll e Marenco (2018, p. 19) sustentam que "[...] o status adquirido pelos governos municipais traduziu-se em maior autonomia político-jurídica" em um contexto de descentralização informada pela negação da extrema centralização política ensejada pelas experiências autoritárias.

Voltemos, agora, o olhar diretamente aos municípios. Partindo das transformações introduzidas pela Constituição, exploremos a heterogeneidade, as novas atribuições e algumas capacidades estatais que têm impacto nas atividades de planejamento.

\section{OS MUNICÍPIOS BRASILEIROS E O PLANEJAMENTO: CONTEXTO, LIMITES E POTENCIALIDADES}

A Constituição Federal de 1988 provocou um conjunto de mudanças políticas e institucionais no Brasil. No que concerne à forma de distribuição de poder pelo território, instalou-se um modelo federativo composto por três entes federados autônomos e interdependentes: União, estados e municípios. Tal modelo foi resultado da combinação de forças descentralizadoras democráticas com grupos e elites tradicionais que, no momento da redemocratização, aproveitaram o enfraquecimento do governo federal para defender uma agenda de fortalecimento dos governos subnacionais (ABRUCIO, 2005; ALMEIDA, 2005; FALLETI, 2006; GIBSON e FALLETI, 2007; GOULART, 2013).

O processo de descentralização em direção aos entes subnacionais foi amplamente discutido ao longo das últimas décadas (ARRETCHE, 1999, 2012; ARRETCHE e MARQUES, 2002; CAVALCANTE, 2011; DOWBOR, 2015; DUARTE, PESSOTO, GUIMARÃES et al., 2015; FREITAS, 2015; LIMA, QUEIROZ, MACHADO et al., 2012; SÁTYRO, CUNHA e CAMPOS, 2016; SOUZA, 1998). A literatura salienta que a descentralização (seja no planejamento, seja na execução das políticas públicas) foi mais acentuada em determinados campos de políticas públicas, como na saúde, no meio ambiente, na assistência social e na educação. Entretanto, Souza (2004) aponta que o novo sistema de governança local, em que os municípios assumiram a responsabilidade pela implementação de um largo conjunto de políticas públicas, materializou-se de forma desigual entre os municípios brasileiros e sua sustentabilidade ainda não está clara. Já questões de ordem fiscal, legislativa e arrecadatória ficaram predominantemente alocadas no governo central. Em relação à arrecadação de tributos, apesar de os municípios serem os responsáveis por sua gestão fiscal, grande parte deles é altamente dependente das transferências constitucionais (FIRJAN, 2018).

A literatura mencionada indica que a descentralização acentuou a extrema desigualdade de condições políticas, técnicas e financeiras dos municípios brasileiros, tornando o processo altamente intrincado e heterogêneo. Nesse sentido, alguns estudos foram realizados buscando compreender os esforços do governo central em promover canais de cooperação interfederativa e a capacitação dos governos locais com vistas a cumprir as determinações constitucionais (GRIN, 2014; GRIN e ABRUCIO, 2017).

Uma das inovações da Constituição Federal foi a imposição da necessidade de criação de novos instrumentos de planejamento e controle orçamentário para todos os entes federados - até então restrito à União e aos estados. A Carta Constitucional definiu que todos os entes devem elaborar a Lei Orçamentária Anual (LOA), a LDO, além do Plano Plurianual (PPA). Com isso, todos os gastos, investimentos e ações financeiras devem constar nos referidos documentos de planejamento.

Ilustrativamente, observa-se que nas últimas décadas, a elaboração de instrumentos de planejamento setorial tornou-se ainda mais necessária para os municípios brasileiros, visto que tanto a Lei n. 11.445/2007 (BRASIL, 2007), conhecida como a Lei de Saneamento Básico, quanto a Lei n. 12.305/2010 (BRASIL, 2010), que institui a Política Nacional de Resíduos Sólidos (PNRS), estabeleceram que as prefeituras deveriam preparar os seus respectivos Planos Municipais. Ambas as normas postulam que a confecção dos referidos planos é condição necessária para o município receber os recursos da União destinados a essas políticas. Ainda, os municípios que possuem mais de 20 mil habitantes também devem elaborar o Plano Diretor, que dispõe sobre o parcelamento e uso do solo urbano, dentre outras disposições, conforme aponta a Lei no 10.257/2001 (BRASIL, 2001). Assim, além do PPA, LDO e LOA, os municípios também precisaram construir um amplo conjunto de peças de planejamento setorial.

Concomitantemente a esse processo de assunção de atribuições em relação às políticas públicas, a partir da década de 1980, houve um crescimento exponencial do número de municípios: de 3.974 em 1980, para 5.570 em 2010 (TOMIO, 2002, 2005). Conforme se identifica na Tabela 1, a maioria é de pequeno porte: $44 \%$ possuem até 10 mil habitantes e $68 \%$, até 20 mil habitantes (IBGE/MUNIC, 2015). 
Tabela 1

Número de municípios brasileiros e porte populacional

\begin{tabular}{l|c|c}
\hline \multicolumn{1}{|c|}{ Porte populacional } & Quantidade de municípios & $\%$ \\
\hline Até 5.000 & 1.237 & $22,21 \%$ \\
De 5.001 a 10.000 & 1.214 & $21,80 \%$ \\
De 10.001 a 20.000 & 1.377 & $24,72 \%$ \\
De 20.001 a 50.000 & 1.087 & $19,52 \%$ \\
De 50.001 a 100.000 & 353 & $6,34 \%$ \\
De 100.001 a 500.000 & 261 & $4,69 \%$ \\
Mais de 500.000 & 41 & $0,74 \%$ \\
Total & 5.570 & $100 \%$ \\
\hline
\end{tabular}

Fonte: IGBE/MUNIC (2015).

No que se refere à capacidade de planejamento, os dados do IBGE/MUNIC (2015) oferecem um panorama por meio da existência de estrutura administrativa voltada ao planejamento urbano ${ }^{2}$ - presente em $75 \%$ dos municípios brasileiros. Na Tabela 2 é possível verificar que praticamente a totalidade dos municípios com mais de 100 mil habitantes possuem estrutura técnica voltada a essa atividade setorial. De todo modo, chama a atenção que $38 \%$ dos municípios com menos de 5 mil habitantes e $32 \%$ dos que possuem menos de 10 mil habitantes não disponham desta estrutura específica.

Tabela 2

Municípios e estrutura organizacional estatal municipal na área de planejamento urbano

\begin{tabular}{l|c|c|c|c}
\hline \multicolumn{1}{c|}{ Porte populacional } & Possuem & $\%$ & Não possuem & $\%$ \\
\hline Brasil & 4192 & 75,26 & 1378 & 24,74 \\
Até 5.000 & 764 & 61,76 & 473 & 38,24 \\
De 5.001 a 10.000 & 820 & 67,55 & 394 & 32,45 \\
De10 001 a 20.000 & 1049 & 76,18 & 327 & 23,75 \\
De 20 001 a 50.000 & 929 & 85,46 & 158 & 14,54 \\
De 50 001 a 100.000 & 331 & 93,77 & 22 & 6,23 \\
De 100 001 a 500.000 & 257 & 98,47 & 4 & 1,53 \\
Mais de 500. 000 & 41 & 100 & 0 & 0,00 \\
\hline
\end{tabular}

Fonte: IBGE/MUNIC (2015).

Outro ponto a ser ressaltado é que os dados do IBGE/MUNIC não contemplam outras estruturas voltadas ao planejamento, como as específicas para a elaboração do PPA, que é uma peça mais abrangente porque agrega todas as políticas setoriais (finalísticas) e atividades administrativas (intermediárias). A pesquisa volta-se, sobretudo, ao mapeamento das estruturas construídas para a produção do Plano Diretor das cidades. Salienta-se que o planejamento urbano é atividade vinculada à gestão da cidade, integrante, assim, de política setorial. Em relação ao planejamento abrangente, alguns estudos indicam que há grandes carências técnicas e administrativas, especialmente nos municípios de pequeno porte, os quais acabam contratando consultorias para a elaboração do PPA (AZEVEDO e AQUINO, 2016; MARINHO e JORGE, 2015).

\footnotetext{
${ }^{2}$ O IBGE considera as seguintes tipologias para caracterização do conceito "estrutura de planejamento urbano": "secretaria municipal exclusiva", "secretaria municipal em conjunto com outras políticas", "setor subordinado a outra secretaria", "setor subordinado diretamente a chefia do executivo", "órgão da administração indireta" e "não possui estrutura específica".
} 
Somado a isso, é flagrante a extrema dependência financeira de grande parte dos municípios brasileiros das transferências constitucionais, processo que pode comprometer a autonomia municipal. De acordo com a Federação das Indústrias do Rio de Janeiro (2018), três décadas após a promulgação da Constituição Federal, o quadro financeiro dos municípios é de desequilíbrio no volume de receitas e na geração de arrecadação própria: $81,7 \%$ dos municípios não geram sequer $20 \%$ de suas receitas. Além disso, o estudo aponta: quanto menor o município, maior a dependência das transferências federais. A esse respeito, Grin (2014) salienta que a descentralização de responsabilidades pelo desenvolvimento de inúmeras políticas públicas não foi acompanhada da expansão de capacidades de arrecadação e técnico-administrativas.

Nesse debate, cabe inserir algumas informações sobre a profissionalização das burocracias municipais. Os dados da Pesquisa de Informações Básicas (IBGE/MUNIC, 2011) apontaram que 40\% dos funcionários das prefeituras brasileiras possuem nível médio de ensino; $23 \%$, nível fundamental e $28 \%$, ensino superior. Além disso, $7 \%$ são pós-graduados e $2 \%$ não têm instrução formal. Ou seja, observa-se que a maioria dos funcionários das prefeituras não possuíam ensino superior, o que pode afetar a capacidade administrativa.

Portanto se percebem a centralidade e os constrangimentos dos municípios no cenário atual. Por um lado, possuem status de entes federados e a incumbência de desenvolver instrumentos de planejamento a fim de orientar a implementação das políticas públicas em seus territórios; por outro, são altamente heterogêneos e desiguais, embora possuem limitadas capacidades de execução das políticas públicas. Devemos mencionar que a identificação deste cenário promoveu diversas iniciativas de qualificação de gestores locais no que tange ao planejamento, em particular do PPA. Nesse sentido, podemos citar os esforços da Escola Nacional de Administração Pública (ENAP) e do Instituto Brasileiro de Administração Municipal (IBAM).

Por fim, é importante sublinhar o grande número de estudos sobre planejamento no nível do governo central (CARDOSO JUNIOR, 2011), bem como a pouca atenção que a literatura deu à questão do planejamento em nível municipal, conforme veremos a seguir. Importante destacar que, nesse artigo, focamos no que denominamos atividade de planejamento abrangente, isto é, não trataremos de planejamento setorial, operado no âmbito de políticas específicas (saúde, educação, meio ambiente etc.).

\section{PROCEDIMENTOS DE PESQUISA}

Para o cumprimento dos objetivos deste estudo foi realizada uma busca sistematizada de artigos nas bases do Portal Periódicos Capes - que inclui os periódicos indexados no Scientific Electronic Library Online (SciELO). Dessa maneira, certificamo-nos de que os principais periódicos nacionais estariam contemplados. Foram utilizados os descritores "municípios" AND "planejamento" na busca por artigos revisados por pares, oriundos de pesquisa empírica original (excluímos, dessa forma, os ensaios e as revisões de literatura), no idioma português em todo texto (incluindo título, resumo e assunto), no período de 1995 até 2018. Tal procedimento foi realizado em junho de 2018. O método de busca e organização dos estudos, denominado de scoping review, foi inspirado nos trabalhos de Levac, Colquhoun e O'Brien (2010) e de Schaefer, Barbiani, Nora et al. (2018). Para os autores, esse é um tipo de método utilizado quando o objetivo é mapear produções relevantes no campo de interesse e avaliar o conteúdo dessas produções.

Uma limitação desse método é não considerar materiais não indexados, incluindo aí teses, dissertações, capítulos de livros, materiais vinculados a institutos como Fundação Konrad Adenauer, Instituto de Pesquisa Econômica Aplicada, Banco Interamericano de Desenvolvimento etc. No entanto, trabalhando desse modo, tem-se maior controle sobre a qualidade das publicações analisadas, uma vez que o método scoping review considera somente artigos publicados em revistas revisadas por pares, indexados em bases consolidadas no meio acadêmico.

Por meio desse processo localizamos, ao todo, 1.685 artigos. Neste universo, passamos à análise de cada artigo. Os critérios de inclusão foram: pesquisa primária, publicada na íntegra, com objetivo de investigar o processo de planejamento governamental, em sentido abrangente e não setorial, no âmbito municipal no Brasil. Os critérios de exclusão foram os seguintes: ensaios ou revisões teóricas, discussão sobre planejamento governamental no âmbito da União ou dos estados da federação, pesquisas sobre planejamento governamental setorial (restrito ao âmbito de políticas públicas específicas). A dinâmica de seleção foi realizada por dois pesquisadores de forma independente e a revisão final foi realizada por um terceiro.

A partir da leitura do título e do resumo das 1.685 publicações localizadas, constatou-se que, apesar do grande número de estudos resultantes, a maioria tratava de temas como planejamento familiar e ações em saúde, planejamento ambiental, 
planejamento turístico e planejamento de ações na esfera da União. Após esta revisão exaustiva, identificamos 160 estudos que discutiam a temática do planejamento municipal no Brasil. Estes tiveram, adicionalmente, seu conteúdo avaliado; mais uma vez, constatamos que muitos versavam sobre políticas setoriais. Dessa maneira, foram excluídos 154, restando seis artigos que se enquadravam no recorte definido.

Diante do número reduzido de achados, consultamos, adicionalmente, os sumários dos periódicos Revista Planejamento e Políticas Públicas, Revista de Administração Pública, Revista do Serviço Público e Cadernos EBAPE.BR. Posteriormente a esse esforço, obtivemos dois artigos com o emprego dos critérios de seleção. Ao final, somando os resultados dos dois movimentos, nosso corpus de pesquisa foi composto por oito artigos, cuja análise apresentamos a seguir.

\section{RESULTADOS E DISCUSSÃO}

O levantamento realizado mostrou que há grande produção sobre planejamento no que concerne aos setores de políticas públicas, como saúde, educação e meio ambiente. Tal abundância é uma consequência de múltiplos fatores, entre eles a ascensão de perspectivas pluralistas e fragmentadas que tomaram o lugar das abordagens compreensivas no contexto da década de 1970. Ainda, no Brasil, o acréscimo e a consolidação dos direitos promovidos pela Constituição, associados ao desenho federativo trino, catalisaram o interesse e a demanda por saberes técnicos específicos ligados às peculiaridades de cada setor de política pública. O que leva a atenção para as formas de integração dessas múltiplas especificidades em um planejamento mais geral, como se pretende o PPA, por exemplo.

Como expressão de toda essa dinâmica, encontramos oito artigos que tinham no planejamento governamental municipal abrangente seu objeto de estudo e/ou reflexão, conforme Quadro 1.

\section{Quadro 1}

Artigos selecionados e classificação Capes

\begin{tabular}{|c|c|c|c|c|c|}
\hline \multirow{2}{*}{ Autores } & \multirow{2}{*}{ Título } & \multicolumn{3}{|c|}{ Dados do Periódico } & \multirow{2}{*}{ Qualis } \\
\hline & & Nome & Estado & Ano & \\
\hline Souza & $\begin{array}{l}\text { Avaliação do processo de implantação de um plano estratégico } \\
\text { participativo municipal: um estudo de caso }\end{array}$ & $\begin{array}{c}\text { Revista de } \\
\text { Estudos Sociais }\end{array}$ & MT & 1999 & B3 \\
\hline $\begin{array}{l}\text { Oliveira, Oliveira, } \\
\text { Siqueira e Brito }\end{array}$ & $\begin{array}{l}\text { Inovação gerencial em municípios: análise exploratória das práticas } \\
\text { de gestão do plano estratégico de Juiz de Fora }\end{array}$ & $\begin{array}{l}\text { Cadernos } \\
\text { EBAPE.BR }\end{array}$ & SP & 2006 & $\mathrm{~A} 2$ \\
\hline Rezende & $\begin{array}{l}\text { Integração do Plano Plurianual Municipal e o Planejamento Estratégico } \\
\text { Municipal: proposta e experiência de um município paranaense }\end{array}$ & Redes & RS & 2010 & B3 \\
\hline Leite e Rezende & $\begin{array}{l}\text { Modelo de gestão municipal baseado na utilização estratégica de } \\
\text { recursos da tecnologia da informação para a gestão governamental: } \\
\text { formatação do modelo e avaliação em um município }\end{array}$ & $\begin{array}{l}\text { Revista de } \\
\text { Administração } \\
\text { Pública- RAP }\end{array}$ & RJ & 2010 & A2 \\
\hline Marinho e Jorge & $\begin{array}{l}\text { O planejamento local é mais eficiente? Uma análise de } 14 \text { municípios } \\
\text { sergipanos de pequeno porte }\end{array}$ & $\begin{array}{l}\text { Nova } \\
\text { Economia }\end{array}$ & MG & 2015 & B1 \\
\hline Ritter e Grasel & $\begin{array}{l}\text { Estratégias para a busca da Gestão de Excelência: um estudo de caso } \\
\text { no município de Canarana }\end{array}$ & $\begin{array}{l}\text { Revista de } \\
\text { Estudos Sociais }\end{array}$ & MT & 2016 & B3 \\
\hline Ferreira Filho & A Importância do Plano Plurianual Participativo na Gestão Pública & $\begin{array}{l}\text { Revista } \\
\text { Controle }\end{array}$ & CE & 2016 & B4 \\
\hline Azevedo e Aquino & O planejamento em municípios de pequeno porte em São Paulo & $\begin{array}{l}\text { Revista de } \\
\text { Contabilidade } \\
\text { e Organizações }\end{array}$ & SP & 2016 & A2 \\
\hline
\end{tabular}

Fonte: Elaborado pelos autores.

*Classificação de periódicos Capes quadriênio 2013-2016 para Administração Pública e de Empresas, Ciências Contábeis e Turismo. Selecionada a área de melhor classificação. 
Da observação do quadro Quadro 1, podemos tecer algumas reflexões. Os trabalhos distribuem-se num período de quase vinte anos; são, assim, esporádicos, demonstrando alguma sorte de limitação na incorporação deste objeto de estudo, a despeito de sua relevância social. Outro ponto que cabe destacar diz respeito à não repetição de autores, apenas Rezende aparece em dois artigos, uma vez que são essencialmente propositivos. Temos, portanto, uma produção não persistente e pouco institucionalizada.

Em relação aos periódicos, estão distribuídos entre quatro regiões do país e metade deles está enquadrada nos primeiros estratos do Qualis Capes. As áreas temáticas dos periódicos incluem controle externo, desenvolvimento regional, administração e economia; com prevalência das duas últimas. Logo, os estudos inserem-se no campo das ciências sociais aplicadas, lastreados nas áreas que tradicionalmente valorizam e desenvolvem o campo do planejamento. Para reforçar essa ideia, investigamos as áreas de formação dos quatorze autores elencados. Verificamos que: seis são oriundos das áreas de administração e contabilidade; três, da economia; dois, da engenharia da produção; e os demais, das ciências sociais, das ciências da informação, da sociologia e antropologia e da gestão urbana.

Para aprofundar esse assunto, o Quadro 2 mostra alguns elementos da estrutura e do conteúdo dos estudos.

\section{Quadro 2}

Natureza, método e fundamentação teórica nos artigos selecionados

\begin{tabular}{|c|c|c|c|}
\hline Artigo & Natureza & Método & $\begin{array}{c}\text { Fundamentação } \\
\text { teórica }\end{array}$ \\
\hline Souza (1999) & avaliativo & estudo de caso & sim \\
\hline $\begin{array}{c}\text { Oliveira, Oliveira, } \\
\text { Siqueira et al. (2006) }\end{array}$ & descritivo & estudo de caso & sim \\
\hline Rezende (2010) & $\begin{array}{c}\text { exploratório, descritivo, } \\
\text { propositivo }\end{array}$ & estudo de caso & sim \\
\hline Leite e Rezende (2010) & propositivo & estudo de caso \\
\hline Marinho e Jorge (2015) & descritivo & $\begin{array}{c}\text { estudo de casos } \\
\text { múltiplos }\end{array}$ & sim \\
\hline Ritter e Grasel (2016) & exploratório, propositivo & estudo de caso & sim \\
\hline Ferreira Filho (2016) & advocacy & - & sim \\
\hline Azevedo e Aquino (2016) & descritivo & survey & \\
\hline
\end{tabular}

Fonte: Elaborado pelos autores.

O Quadro 2 mostra que os estudos de natureza exploratória, descritiva e propositiva são os mais comuns. Com exceção daqueles que propunham ou defendiam metodologias de planejamento específicas, os demais focavam nos processos de elaboração dos planos. Temos, assim, um campo de investigação ainda incipiente, que não progrediu para estudos envolvendo a descoberta de relações de causalidade. Mais uma vez, sabemos pouco sobre as dinâmicas sociais nesses entes fundamentais de nossa federação e sobre a contribuição do planejamento para a gestão municipal.

O estudo de caso é o método mais mobilizado, e os municípios de pequeno porte receberam maior atenção, conforme o Quadro 3. Sobre isso, os trabalhos partem da hipótese de que nesse tipo de município haveria carência de recursos que limitariam a capacidade de planejamento. 


\section{Quadro 3}

\section{Municípios estudados nos artigos selecionados}

\begin{tabular}{|c|c|c|}
\hline Artigo & Município & $\begin{array}{c}\text { População } \\
\text { estimada (2018)* }\end{array}$ \\
\hline Souza (1999) & Doutor Pedrinho (SC) & 4.013 \\
\hline Oliveira, Oliveira, Siqueira et al. (2006) & Juiz de Fora (MG) & - \\
\hline Rezende (2010) & Não informado. & 1.917 .185 \\
\hline Leite e Rezende (2010) & Curitiba & 21.311 \\
\hline Marinho e Jorge (2015) & $\begin{array}{c}\text { 14 municípios do Sergipe } \\
\text { com até 20 mil habitantes }\end{array}$ \\
\hline Ritter e Grasel (2016) & Canarana (MT) pequeno porte & - \\
\hline Ferreira Filho (2016) & - & - \\
\hline Azevedo e Aquino (2016) & com até 50 mil habitantes & \\
\hline
\end{tabular}

Fonte: Elaborado pelos autores.

*A partir dos dados do IBGE (2015).

No que se refere à fundamentação teórica, investigamos quais teorias e/ou conceitos estavam sendo mobilizados nos trabalhos. Note-se que um deles não apresentava referencial teórico. Nesse caso, a abordagem é normativa, o autor enfoca, brevemente, as leis e normas que orientam o PPA e o PPA Participativo. Nos demais artigos, encontramos os modelos expostos no Quadro 4.

\section{Quadro 4}

\section{Fundamentos teórico-conceituais dos artigos selecionados e explicitação do contexto do planejamento no Brasil}

\begin{tabular}{|c|c|c|}
\hline Artigo & Fundamentação teórica & $\begin{array}{c}\text { Contexto do } \\
\text { planejamento } \\
\text { municipal no Brasil }\end{array}$ \\
\hline Souza (1999) & Planejamento: Estratégico, Municipal, Participativo e Social & sim \\
\hline $\begin{array}{c}\text { Oliveira, Oliveira, } \\
\text { Siqueira et al. (2006) }\end{array}$ & Planejamento: Público, Urbano, Estratégico Municipal & sim \\
\hline Rezende (2010) & Planejamento Estratégico Municipal & sim \\
\hline Leite e Rezende (2010) & $\begin{array}{c}\text { Business intelligence, Balanced Scorecard, } \\
\text { customer relationship management, business process } \\
\text { management, group decision support system }\end{array}$ & não \\
\hline Marinho e Jorge (2015) & Planejamento Municipal \\
\hline Ritter e Grasel (2016) & $\begin{array}{r}\text { Planejamento: Estratégico, Estratégico Municipal, } \\
\text { Estratégico Situacional }\end{array}$ & não \\
\hline Ferreira Filho (2016) & não \\
\hline Azevedo e Aquino (2016) & Public Financial Management & sim \\
\hline
\end{tabular}

Fonte: Elaborado pelos autores.

O Quadro 4 indica alguma dispersão teórica nesse grupo de artigos. Contudo se destaca o Planejamento Estratégico, o qual surge direta e indiretamente na base de modelos, como o Planejamento Estratégico Municipal. De outra forma, os artigos que utilizam o Planejamento Municipal tomam o município como escala e recorrem a definições clássicas de planejamento. Nessa questão, os artigos convergem: o planejamento é percebido como um meio/instrumento para a mudança social gerenciada. Entende-se que ele se conforma em um processo intencional e deliberado de construção de objetivos e instrumentos de ação com vistas a promover a melhoria da vida em sociedade. Em tal processo, comumente, a participação da sociedade é valorizada.

Chama a atenção a pouca utilização do Planejamento Estratégico Situacional, elaborado por Carlos Matus. Trata-se de um modelo de planejamento governamental criado especificamente para lidar com as estruturas e as dinâmicas que imperam nos Estados. De forma geral, métodos e instrumentos do setor privado aparecem na base do referencial destes artigos ou 
mesmo diretamente. Embora apresentem referenciais teóricos, estes não são utilizados para análise dos dados. Portanto os resultados dos estudos são, essencialmente, descritivos e os modelos e instrumentos surgem como um dever ser. Ou seja, há um viés normativo, e o parâmetro mais valorizado provém do Planejamento Estratégico.

Averiguamos, também, se os artigos apresentavam o contexto do planejamento nos municípios: verificou-se que três deles não faziam tal discussão. Nos demais, esta informação aparece, principalmente, de duas formas: contexto normativo, destacando as leis sobre planejamento; e contexto histórico, com foco na trajetória dos municípios frente às mudanças em seu status na federação. As duas abordagens aparecem interligadas, sendo a primeira a mais recorrente. Desse modo, as análises sobre planejamento municipal estão fortemente lastreadas nos objetivos e formas definidos pelas normas formais. Tal constatação fortalece o argumento da prevalência de um caráter normativo nestes estudos, em detrimento de um direcionamento bottom-up. Em outras palavras, os estudos percebem os municípios como instâncias executoras de regras gerais, e o foco se mantém nestas.

Por fim, no que tange aos resultados dos estudos, encontramos três linhas de conclusões, conforme segue. Três estudos destacaram aspectos positivos dos processos observados. Nas palavras dos autores:

[...] verifica-se que a abordagem de PEP [Planejamento Estratégico Participativo] [...], aplicada no município de Doutor Pedrinho foi viável, atingindo os principais objetivos propostos, mesmo que apenas parte desses objetivos tenham sido alcançados (SOUZA, 1999, p. 28).

O Plano Estratégico de Juiz de Fora, além de vigorar por mais de um mandato, pôde contribuir para a reeleição do prefeito que o promoveu, [...]. [...]. O Plano JF representou para a cidade um momento de reflexão, onde atores heterogêneos discutiram problemas comuns. Através do PlanoJF, a prefeitura ampliou sua capacidade de ação, apresentado urna alterativas a tradicional resposta 'não há recursos' (OLIVEIRA, OLIVEIRA, SIQUEIRA et al., 2006, p. 15).

Observou-se que nunca o Brasil deu tanto valor à participação popular no processo de planejamento governamental quanto nos últimos anos [...]. Conseguiu-se alcançar o objetivo deste trabalho, e responder a problematização levantada, ao se perceber ao longo deste artigo, que a União, os Estados e os municípios brasileiros estão tratando o Plano Plurianual Participativo (PPP) em suas gestões para a melhoria da gestão pública, de uma forma bem dinâmica [...] (FERREIRA FILHO, 2016, p. 158-159).

Uma segunda linha de resultados despontou em dois estudos propositivos, os quais concluíam pela relevância e funcionalidade dos modelos de planejamento e gestão recomendados:

Um dos objetivos deste artigo foi propor formas de integração entre PPAM [Plano Plurianual Municipal] e o PEM [Plano Estratégico Municipal]. Foram apresentados dois modelos com respectivas variáveis que comprovaram a integração proposta. [...]. O segundo objetivo deste artigo foi demonstrar as relações entre os projetos PPAM e PEM em um município paranaense. $O$ estudo de caso reitera a necessidade e a viabilidade da integração desses projetos por meio das relações descritas a partir do protocolo de pesquisa definido (REZENDE, 2010, p. 115).

A viabilidade da implantação desse modelo em diversos municípios, [...], reside na flexibilidade e modulação proporcionada pelos constructos. Da forma como foi projetado, o modelo permite o atendimento das necessidades e prioridades específicas de cada gestão. Além disso, as diversas customizações empregadas podem estar baseadas em conceitos da iniciativa privada - que, a propósito, originaram o modelo proposto. A competitividade de mercado impele as organizações a práticas sempre mais efetivas, que devem ser aproveitadas pela iniciativa pública (LEITE e REZENDE, 2010, p. 490).

A terceira linha de conclusões advém de três artigos que apresentavam estudos voltados ao diagnóstico de processos de planejamento. Eles apontaram para os constrangimentos e as limitações que influenciaram o desempenho dos municípios no desenvolvimento das tarefas relacionadas ao planejamento.

[...] o planejamento na maioria nos pequenos municípios (de modo específico no Estado de Sergipe) é bastante incipiente, ficando restrito à elaboração do PPA, da LDO e da LOA, de forma padronizada pelas consultorias ou pelos escritórios dedicados à contabilidade pública. [...]. O estudo revelou também a falta de conhecimento, tanto por parte dos prefeitos como dos presidentes das Câmaras de Vereadores, 
dos principais instrumentos de planejamento municipal. [...]. A pesquisa de campo mostrou também que a participação da população na tomada de decisões e na fiscalização da gestão é ainda bastante incipiente (MARINHO e JORGE, 2015, p. 139).

[Esta pesquisa] [...] ratifica as hipóteses da falta de cultura de planejamento, recursos humanos de modo geral com pouca qualificação, mas a hipótese de resistência à elaboração de planejamento foi refutada [...] (RITTER e GRASEL, 2016, p. 276).

[...] a dinâmica orçamentária vigente, nos municípios analisados, ainda segue o modelo de inputbased budget com pouca ou nenhuma avaliação da eficiência dos programas, e com baixa utilização das metas físicas e indicadores desenvolvidos no orçamento. Portanto, tais municípios demonstram possuir baixa capacidade de assimilação das reformas recentes que o Brasil propôs em seu ciclo PFM [Public Financial Management]. Os resultados mostram que [...] a falta de setores específicos dedicados à função do planejamento em geral coloca esta função sob a responsabilidade do contador, lotado na Secretaria de Finanças. O planejamento é desenvolvido quase sempre de forma centralizada, com pouca participação das demais secretarias e órgãos da Administração Indireta. [...]. Observou-se ainda um baixo envolvimento do legislativo local na elaboração e aprovação do orçamento [...], além de uma baixa participação popular no processo. Quanto ao controle externo, eventuais deficiências no orçamento não têm sido alvo recorrente de reprovação de contas, o que incentiva a baixa maturidade do processo (AZEVEDO e AQUINO, 2016, p. 74).

Enfim, a despeito da importância e da centralidade dos municípios na federação brasileira, pouco sabemos sobre suas capacidades para empreender as atividades de planejamento esperadas e sobre as fontes de suas dificuldades. Levantam-se hipóteses sobre a existência de incapacidades diversas, e devemos avançar para melhor caracterizá-las, descobrir suas causas, para, então, construir meios de ação mais ajustados, eficientes e efetivos.

Em contrapartida, os estudos analisados exibem um direcionamento top-down, no sentido de que partem da aceitação acrítica dos elementos definidos na estrutura normativa formal, preocupando-se em avaliar/discutir ou propor soluções para que tais determinações sejam cumpridas. Aqui surge um paradoxo: como propor formas de cumprir tais normas se pouco sabemos sobre como funcionam os municípios? Aparentemente ainda estamos mobilizando uma visão passiva deste, agora, ente federado; resquícios culturais da centralização pretérita.

Percebeu-se que as lentes analíticas não estavam sobre os municípios propriamente, mas sobre sua capacidade de seguir as normas gerais; não que não seja relevante, mas é apenas um lado da moeda. Ou seja, os estudos sobre como funcionam os municípios podem se beneficiar de um olhar bottom-up, enfocando as estruturas e dinâmicas locais como forma de compreender como formulam e executam normas e políticas públicas. Aqui encontramos um espaço de oportunidade para o desenvolvimento de uma agenda de pesquisa conectada com as demandas e necessidades do país.

\section{CONSIDERAÇÕES FINAIS}

Nesta pesquisa, averiguou-se que o planejamento governamental foi, historicamente, atribuição e prática dos governos centrais. No Brasil, esse cenário mudou com a democratização e ganhou corpo na Constituição Federal de 1988. Os municípios, alçados a entes federados, assumiram uma série de competências em relação às políticas públicas e às atividades gerenciais que lhes garantiriam qualidade e efetividade. Dentre estas, o planejamento é, por certo, uma das mais importantes.

Neste quadro, ganha relevo a ampliação do conhecimento sobre as estruturas e as dinâmicas desenvolvidas para dar concretude a estas novas competências. No entanto, verificou-se escassa produção científica sobre as práticas de planejamento não setorial nos municípios brasileiros. Identificamos, assim, que a "comunidade científica" nessa área de estudos ainda está por se formar e/ou fortalecer, já que não localizamos um corpo de conhecimento acumulado sobre a temática do planejamento em âmbito municipal, e os artigos analisados careciam de unidade teórica e metodológica.

Nesse caminho, para pesquisas futuras, é relevante investigar os sentidos do planejamento nos municípios, para além das acepções normativas formais. Outra questão promissora é a forma de integração entre os diversos planejamentos setoriais, de forma a produzir o PPA. Também deve-se levar em consideração a grande heterogeneidade dos municípios no Brasil e como isso se materializa nos processos de planejamento. 


\section{REFERÊNCIAS}

ABRUCIO, F. L. A coordenação federativa no Brasil: a experiência do período FHC e os desafios do governo Lula. Revista de Sociologia e Política, n. 24, p. 41-67, jun. 2005.

ALMEIDA, M. H. T. Recentralizando a federação? Revista de Sociologia e Política, n. 24, p. 29-40, jun. 2005.

ARRETCHE, M. Políticas sociais no Brasil: descentralização em um Estado federativo. Revista Brasileira de Ciências Sociais, v. 14, n. 40, p. 111-141, 1999.

ARRETCHE, M. Democracia, Federalismo e Centralização no Brasil. Rio de Janeiro: Fiocruz /FGV, 2012.

ARRETCHE, M.; MARQUES, E. Municipalização da saúde no Brasil: diferenças regionais, poder do voto e estratégias de governo. Ciência \& Saúde Coletiva, v. 7, n. 3, p. 455-479, 2002.

AZEVEDO, R.; AQUINO, A. O planejamento em municípios de pequeno porte em São Paulo. Revista de Contabilidade e Organizações, v. 10, n. 26, p. 63-76, 2016.

BRASIL. Decreto-lei no 200, de 25 de fevereiro de 1967. Dispõe sobre a organização da Administração Federal, estabelece diretrizes para a Reforma Administrativa e dá outras providências. Brasília, 07 dez. 1966. Disponível em: <http://www.planalto.gov.br/ccivil_03/DecretoLei/Del0200.htm>. Acesso em 06 out. 2018.

BRASIL. Lei $\mathbf{n}^{\circ} \mathbf{1 1 . 4 4 5}$, de 5 de janeiro de 2007. Estabelece diretrizes nacionais para o saneamento básico. Disponível em: <http://www. planalto.gov.br/ccivil_03/_Ato2007-2010/2010/Lei/L12305.htm>. Acesso em 03 de novembro de 2018.

BRASIL. Lei no. 10.257, de 10 de julho de 2001. Regulamenta os arts. 182 e 183 da Constituição Federal estabelece diretrizes gerais da política urbana e dá outras providências. Diário Oficial da União. Brasília, DF: Imprensa Oficial, 2001. Disponível em: <http://www. planalto.gov.br/ccivil_03/leis/LEIS_2001/L10257.htm>. Acesso em 03 de novembro de 2018.

BRASIL. Lei № 12.305, de 2 agosto de 2010. Institui a Política Nacional de Resíduos Sólidos. Disponível em: <http://www.planalto.gov.br/ ccivil_03/_ato2007-2010/2010/lei/l12305.htm>. Acesso em 03 de novembro de 2018.

CARDOSO JUNIOR, J. C. Planejamento Governamental e Gestão Pública no Brasil: elementos para ressignificar o debate e capacitar o estado. Brasília: Ipea, 2011.

CARDOSO JUNIOR, J. C.; SANTOS, E. A. V. Planejamento governamental e aparato burocrático no governo federal brasileiro: disjuntivas críticas e baixo desempenho institucional - questões para uma agenda de pesquisa e intervenção. In: PIRES, R.; LOTTA, G.; OLIVEIRA, V. E. (Orgs.). Burocracia e políticas públicas no Brasil: interseções analíticas. Brasília: Ipea: Enap, 2018. p. 328-253.

CAVALCANTE, P. Descentralização de políticas públicas sob a ótica neoinstitucional: uma revisão de literatura. Revista de Administração Pública, v. 45, n. 6, p. 1781-1804, 2011.

COUTO, L. F.; MAGALHÃES, A. Iniciativas, funções e estruturas de planejamento federal. Boletim de Análise Político-Institucional, n. 12, jul.-dez. 2017. Brasília: IPEA, 2017. p. 37-42.
DOWBOR, L. Governabilidade e descentralização. Revista do Serviço Público, v. 45, n. 1, p. 95-117, 2015.

DUARTE, L. S. et al. Regionalização da saúde no Brasil: uma perspectiva de análise. Saúde e Sociedade, v. 24, n. 2, p. 472-485, 2015.

EVANS, P. Autonomia e Parceria: Estados e transformação industrial. Rio de Janeiro: UFRJ, 2004.

FALLETI, T. Efeitos da descentralização nas relações intergovernamentais: o Brasil em perspectiva comparada. Sociologias, v. 8, n. 16, p. 46-85, 2006.

FERREIRA FILHO, W. R. A importância do plano plurianual participativo na gestão pública. Revista Controle: Doutrinas e artigos, v. 12, n. 2, p. 147-164, 2016.

FIRJAN. Criação de Municípios: mais impostos e menos serviços à população. Rio de Janeiro: FIRJAN, 2018. Disponível em: <https:// www.firjan.com.br/>. Acesso em: 06 set. 2018.

FREITAS, L. O. Políticas públicas, descentralização e participação popular. Revista Katálysis, v. 18, n. 1, p. 113-122, 2015.

GIBSON, E. L.; FALLETI, T. G. La unidad a palos: Conflicto regional y los orígenes del federalismo argentino. Postdata, n. 12, p. 171204, ago. 2007. Disponível em: <http://www.scielo.org.ar/scielo. php?script=sci_arttext\&pid=S1851-96012007000100008\&Ing=es\& $\mathrm{nrm}=\mathrm{iso}>$. Acesso em: 06 set. 2018.

GOULART, J. O processo Constituinte e Arranjo federativo. Lua Nova, n. 88, p. 185-215, 2013.

GRIN, E. J. Trajetória e avaliação dos programas federais brasileiros voltados a promover a eficiência administrativa e fiscal dos municípios. Revista de Administração Pública, v. 48, n. 2, p. 459-480, 2014.

GRIN, E. J.; ABRUCIO, F. L. Quando "feds" e "locals" não falam a mesma língua: uma análise sobre dissonâncias na cooperação federativa. Cadernos EBAPE.BR, v. 15, n. 3, p. 694-719, 2017.

IBGE/MUNIC. Perfil dos Municípios Brasileiros. Brasília: IBGE, 2015.

LEITE, L. O.; REZENDE, D. A. Modelo de gestão municipal baseado na utilização estratégica de recursos da tecnologia da informação para a gestão governamental: formatação do modelo e avaliação em um município. Revista de Administração Pública, v. 44, n. 2, p. 459-493, 2010.

LEVAC, D.; COLQUHOUN, H.; O'BRIEN, K. K. Scoping studies: advancing the methodology. Implementation science, v. 5, n. 69, p. 1-9, 2010.

LIMA, L. D. et al. Descentralização e regionalização: dinâmica e condicionantes da implantação do Pacto pela Saúde no Brasil. Ciência \& Saúde Coletiva, v. 17, p. 1903-1914, 2012.

MARENCO, A.; STROHSCHOEN, M. T. B. Abrindo a caixa-preta da gestão municipal: variações no perfil de burocracias governamentais locais. In: MARENCO, A.; NOLL, M. I. (Orgs.). A política, as políticas e os controles: como são governadas as cidades brasileiras. Porto Alegre: Tomo Editorial, p. 31-48, 2018.

MARINHO, A. P.; JORGE, M. A. O planejamento local é mais eficiente? Uma análise de 14 municípios sergipanos de pequeno porte. Nova Economia, v. 25, n. 1, p. 123-142, 2015. 
Planejamento governamental nos municípios brasileiros: em direção a uma agenda de pesquisa
Luciana Leite Lima | Lizandro Lui Gianna Vargas Reis Salgado Dias | Luciana Pazini Papi Diogo Joel Demarco
NOLL, M. I.; MARENCO, A. O que sabemos e o que ainda não sabemos sobre política municipal? In: MARENCO, A.; NOLL, M. I. (Orgs.). A política, as políticas e os controles: como são governadas as cidades brasileiras. Porto Alegre: Tomo Editorial, 2018. p. 11-30.

OLIVEIRA, V. C. S. et al. Inovação gerencial em municípios: análise exploratória das práticas de gestão do plano estratégico de Juiz de Fora. Cadernos EBAPE.BR, v. 4, n. 4, p. 2-17, 2006.

REZENDE, D. A. Integração do Plano Plurianual Municipal e o Planejamento Estratégico Municipal: proposta e experiência de um município paranaense. REDES: Revista do Desenvolvimento Regional, v. 15 , n. 2, p. 92-119, 2010.

REZENDE, F. Planejamento no Brasil: auge, declínio e caminhos para a reconstrução. In: CARDOSO JUNIOR, J. C. A reinvenção do planejamento governamental no Brasil. 4. ed. Brasília: Ipea, 2011. p. 177-237.

RITTER, E. O.; GRASEL, D. Estratégias para a busca da gestão de excelência: um estudo de caso no município de Canarana. Revista de Estudos Sociais, v. 18, n. 36, p. 251-279, 2016.

SADDI, F. C. Política e economia no federalismo do governo Geisel. Revista de Economia Política, v. 23, n. 2, p. 90, 2003.

SÁTYRO, N. G. D.; CUNHA, E. S. M.; CAMPOS, J. Análise espacial da burocracia da assistência social nos municípios brasileiros: notas para uma reflexão sobre a capacidade de implementação dessa política. Opinião Pública, v. 22, n. 2, p. 286-317, 2016.

SCHAEFER, R. et al. Políticas de Saúde de adolescentes e jovens no contexto luso-brasileiro: especificidades e aproximações. Ciência \& Saúde Coletiva, v. 23, n. 9, p. 2849-2858, set. 2018.

SOUZA, A. R. Avaliação do processo de implantação de um plano estratégico participativo municipal: um estudo de caso. Revista de Estudos Sociais, v. 1, n. 1, p. 7-30, 1999.

SOUZA, C. Intermediação de interesses regionais no brasil: o impacto do federalismo e da descentralização. Dados, v. 41, n. 3, p. 569592,1998

SOUZA, C. Governos locais e gestão de políticas sociais universais. São Paulo Perspectiva, São Paulo, v. 18, n. 2, p. 27-41, jun. 2004. Disponível em: <http://www.scielo.br/scielo.php?script=sci_ arttext\&pid=S0102-88392004000200004\&lng=en\&nrm=iso>. Acesso em: 30 jun. 2019.

TOMIO, F. R. L. A criação de municípios após a Constituição de 1988. Revista Brasileira de Ciências Sociais, v. 17, n. 48, p. 61-69, 2002.

TOMIO, F. R. L. Federalismo, municípios e decisões legislativas: a criação de municípios no Rio Grande do Sul. Revista de Sociologia e Política, n. 24, p. 123-148, 2005.

Luciana Leite Lima

ORCID: https://orcid.org/0000-0002-8761-4114

Doutora em Ciências Sociais pela Universidade Estadual de Campinas (Unicamp); Professora associada na Universidade Federal do Rio Grande do Sul (UFRGS), Porto Alegre - RS, Brasil. E-mail: lucianaleitelima@gmail.com

Lizandro Lui

ORCID: https://orcid.org/0000-0002-9276-247X

Doutor em Sociologia pela Universidade Federal do Rio Grande do Sul (UFRGS); Pesquisador do Instituto de Pesquisa Econômica Aplicada (IPEA), Brasília - DF, Brasil. E-mail: lizandrolui@gmail.com

Gianna Vargas Reis Salgado Dias

ORCID: https://orcid.org/0000-0001-5075-4546

Mestra em Políticas Públicas pela Universidade Federal do Rio Grande do Sul (UFRGS); Pesquisadora do Núcleo de Pesquisa em Gestão Municipal (Nupegem) na Universidade Federal do Rio Grande do Sul (UFRGS), Porto Alegre - RS, Brasil. E-mail: gvargasreis@gmail.com

Luciana Pazini Papi

ORCID: https://orcid.org/0000-0002-9112-3967

Doutora em Ciência Política pela Universidade Federal do Rio Grande do Sul (UFRGS); Professora adjunta na Universidade Federal do Rio Grande do Sul (UFRGS), Porto Alegre - RS, Brasil. E-mail: luppapi@yahoo.com.br

Diogo Joel Demarco

ORCID: https://orcid.org/0000-0002-8327-321X

Doutor em Educação pela Universidade de São Paulo (USP); Professor associado na Universidade Federal do Rio Grande do Sul (UFRGS), Porto Alegre - RS, Brasil. E-mail: diogo.demarco@ufrgs.br 